\title{
GUMMA OF THE PENIS*
}

\author{
BY \\ R. D. CATTERALL, C. D. COLLINS, AND A. REDMOND \\ From the Whitechapel Clinic, London Hospital, the Special Clinic, St. Thomas's Hospital, and the Special Clinic, \\ St. Bartholomew's Hospital, London
}

Gumma of the penis is generally regarded as a rare condition and on that account it is likely to be overlooked as a possibility in the diagnosis of penile sores. As far as we can ascertain only eleven cases of penile gummata have been reported in the world literature during the past 40 years. In many of these cases the diagnosis was made on clinical grounds and not substantiated by histological proof.

Berdal (1902) described two types of gumma of the penis, one being a classical gumma and the other a "tuberculoid" type. Fournier (1906) also described two types: a typical gumma, and a diffuse gummatous infiltration. He further subdivided the diffuse gummatous infiltration into a "sclérogommeuse" type, which was probably similar to Berdal's "tuberculoid" type, and a "forme scléreuse" which often involved the urethra and caused a generalized fibrosis throughout the penis. Wise $(1918,1919)$ demonstrated two cases in which the diagnosis was made on clinical grounds. Mariantschik (1929) and Koyosu (1929) each described a case of this condition. Hahn (1947) reported a case in which treatment with arsenic and bismuth had been given 10 years previously for a penile sore which healed satisfactorily, but in which an ulcer had now appeared at the same site. This ulcer failed to respond to penicillin, but finally healed after a course of injections of arsenoxide and bismuth. Schmidt, Jaramillo, and Donghi (1950) reported one case, and Chapuis, Colé, and Duperrat (1954) reported two cases with gummata occurring at the site of the original chancre. In all three cases the diagnosis was confirmed microscopically.

The present series comprises five cases of gumma of the penis, which have been treated recently at three London teaching hospitals. Three of the patients attended the Whitechapel Clinic, London Hospital, one St. Thomas's Hospital, and one St. Bartholomew's Hospital. One patient also had a gumma of the lung. Four of the five patients gave no history of primary or secondary lesions, and in

\footnotetext{
* Received for publication May 10, 1957.
}

two, microscopical examination of biopsy specimens showed changes compatible with gummatous ulceration.

Case 1, a British West Indian, aged 35, attended the Special Treatment Centre, St. Bartholomew's Hospital, complaining of a sore on his penis which had been present for 1 month. He gave a history of treatment for "bad blood" 6 years previously for which he had been given a few injections. His last risk of infection had been 2 months previously and there had been profuse bleeding from the penis following intercourse. He also complained of a slight cough during the previous few weeks.

Examination.-The prepuce was phimotic with a small ulcer at its edge and indurated areas under and around the ulcer. There was a small area of leucoplakia surrounding and adjacent to the ulcer, with minimal enlargement of the right inguinal lymphatic glands. No other abnormality was found on general physical examination apart from the presence of atrophic macules on the trunk.

Laboratory Investigations.-Dark-ground examination of serum from the ulcer showed no $T$. pallidum. The blood Wassermann reaction (WR) and Kahn test were positive on two occasions. The cerebrospinal fluid was normal. $X$-ray examination of the heart was normal, but the radiological report on the lung fields (Fig. 1, opposite) was as follows:

There is a large opacity in the lingula of the left upper lobe. The upper border is moderately well defined. There is a small pleural reaction at the base. There is a little fine linear shadowing just above the opacity suggesting fibrosis, and, in view of the history, this may be a gumma of the lung. However, there are no very characteristic appearances. Tomography would be advisable.

The patient was also seen by a chest physician who considered that, in view of the history, the lung lesion was most likely to be a gumma.

Treatment.-To exclude the possibility of malignancy in the genital sore, the patient was admitted for circumcision and the excised prepuce was sent for biopsy. The report on the microscopical examination was as follows:

Sections show a dense inflammatory infiltration but the appearances here are not those of an epithelioma; there 


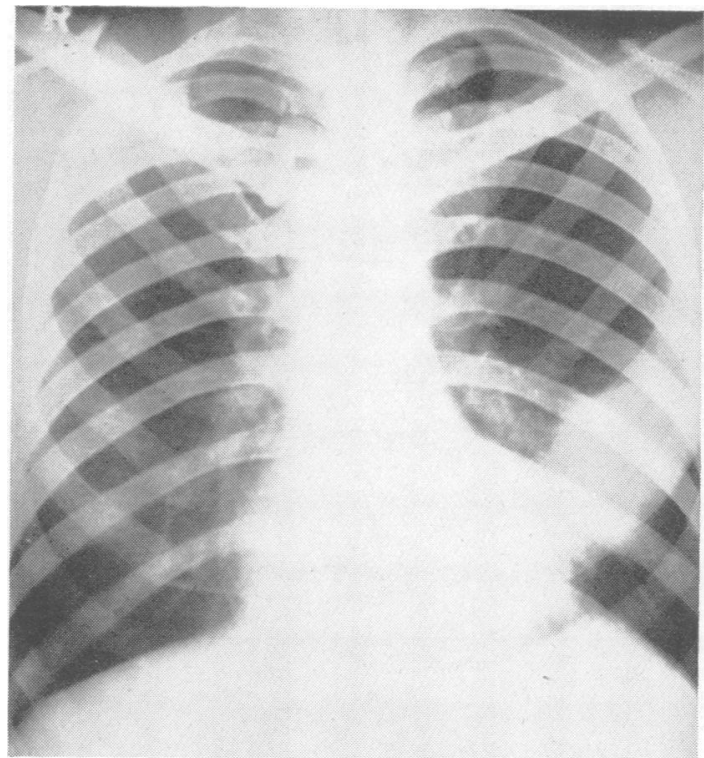

FIG. 1.-Gummatous cavity of upper lobe of left lung. (CASE 1)

is no evidence of gummatous necrosis but occasional epithelial and giant cell foci are present. The appearances are compatible with an early gummatous lesion.

The patient was treated with procaine penicillin in watery solution, 600,000 units intramuscularly daily for 12 days, and $0 \cdot 3 \mathrm{~g}$. bismuth intramuscularly once weekly for 10 weeks.

Radiographs of the chest show the condition of the lungs before treatment (Fig. 1) and on the 8th day of penicillin therapy (Fig. 2).

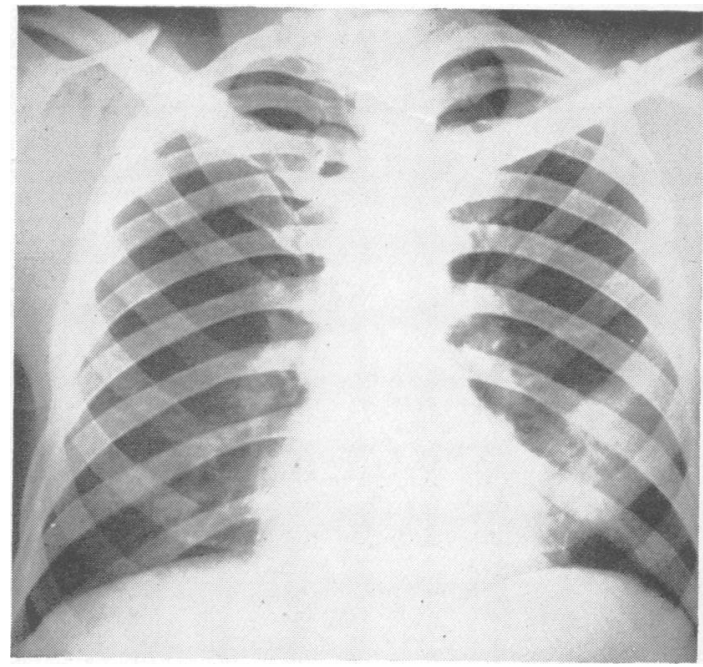

FIG. 2.-Lung fields 8 days after starting penicillin therapy.
The radiologist's report on Fig. 2 was as follows:

The opacity in the lingula is very much smaller and has lost its well-defined outline. Tenting of the diaphragm has disappeared.

The rapid response to treatment tends to confirm the diagnosis of gumma.

Case 2, a white male, aged 46, was referred to the Whitechapel Clinic, London Hospital, from the Royal National Throat, Nose, and Ear Hospital because of gummatous ulceration of the nasal septum. Four years previously he had been seen at the National Hospital, Queen Square, and had been found to have general paralysis of the insane with strongly positive blood tests and characteristic changes of the cerebrospinal fluid. He had been treated at Horton Hospital with malarial therapy with considerable improvement in his mental condition. He denied previous penile lesions or skin rashes.

Examination.-He was a pale, poorly-nourished man with moderate collapse of the nose. There was a large gumma of the nasal septum with marked destruction of the septal cartilage. The penis was almost completely destroyed by gummatous ulceration and there was an infected urinary fistula in the peno-scrotal angle (Fig. 3). The pubic skin showed an extensive papulo-squamous syphilide with a serpiginous border. The inguinal glands

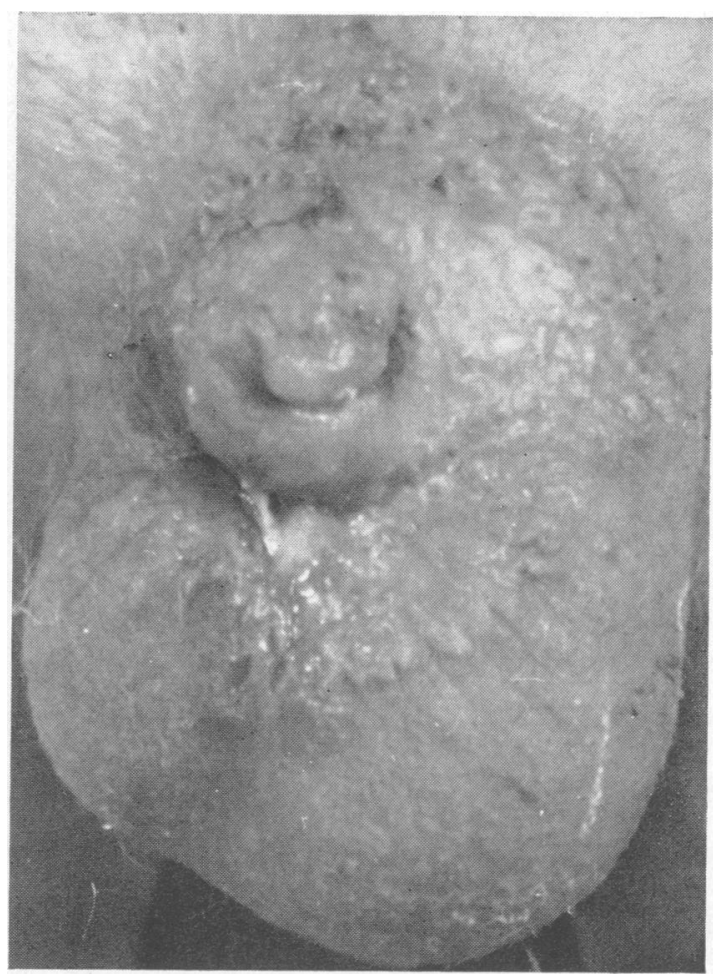

Fig. 3.-Destruction of penis from gummatous ulceration. (CASE 2) 
were not enlarged; both testicles were atrophic; there was marked slurring of speech and a fine tremor of the lips and tongue. The pupils were irregular and unequal, but reacted normally to light and accommodation. The tendon reflexes in the lower limbs were normal, the plantar reflexes were both flexor, and there were no sensory disturbances.

Laboratory Investigations.-The WR was positive and Price's precipitation test (PPR) positive 1 in 160, in the blood serum. The cerebrospinal fluid showed 7 cells per $\mathrm{ml}$. and $25 \mathrm{mg}$. protein, a positive WR, and a normal Lange curve. An $x$ ray of the chest and cardioscopy showed nothing abnormal.

Treatment.-He was given weekly injections of $0.2 \mathrm{~g}$. bismuth to a total dose of $4 \mathrm{~g}$., 6 mega units penicillin in divided doses over a period of 12 days, and a mixture containing $30 \mathrm{gr}$. potassium iodide three times a day by mouth. With this treatment the pubic lesions healed, leaving considerable destruction and scarring. The urinary fistula remained patent and the patient passed urine both through the penile stump and through the urinary fistula.

Progress.-He was admitted to the London Hospital 5 years later and was found to have signs of tabes dorsalis; he had developed Charcot's arthropathy of the right knee and a tabetic bladder. Tests of the cerebrospinal fluid were normal.

Case 3, a British West Indian, aged 35, reported to the Lydia Clinic, St. Thomas's Hospital, complaining of a penile sore which had been present for the past 3 weeks and was now getting bigger in spite of his own treatment at home with Dettol.

In the past, he had been treated with one injection of penicillin for gonorrhoea at the age of 19, and apart from this denied any serious illnesses, including yaws. He had run risks of infection several times in the period of 2 months before reporting to the clinic.

Examination.-He was found to have a large sloughing ulcer on the corona of the penis measuring approximately $2 \times \frac{1}{2} \times \frac{1}{4}$ in. with surrounding oedema (Fig. 4). In addition, he had enlarged, discrete, non-tender glands in both groins. General physical examination revealed no abnormality apart from scars on his legs, which he stated were traumatic in origin.

Laboratory Investigations.-Dark-ground examination of serum from the ulcer on three separate slides failed to show $T$. pallidum. The blood WR and PPR were positive and an Itô-Rienstierna test in his right forearm was strongly positive at 24 and 48 hours.

Treatment.-A diagnosis of chancroid was made and the patient was started on a course of sulphonamide therapy ( $5 \mathrm{~g}$. daily in divided doses for 5 days), together with local saline soaks. During this time the lesion failed

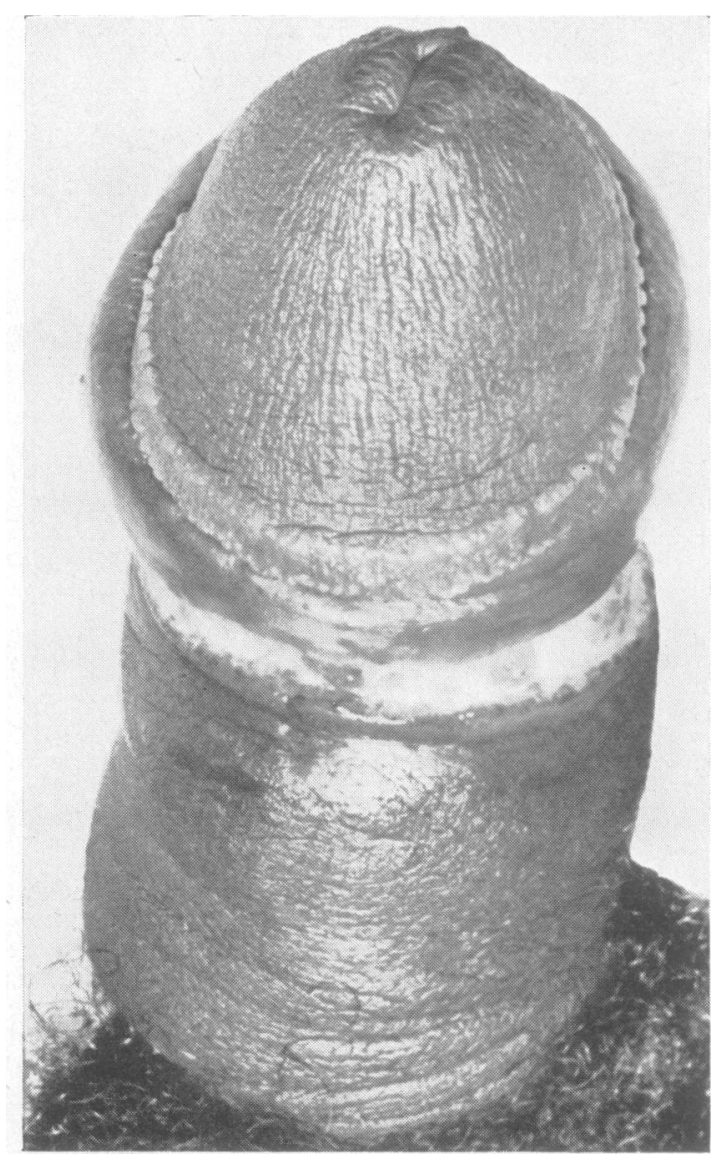

Fig. 4.-Gumma of coronal sulcus.

(CASE 3)

to heal, and repeated dark-ground examination showed no $T$. pallidum in serum from the ulcer. The blood WR and Kahn test remained positive and the PPR was positive to a titre of 1 in 128. The ulcer had now become bigger and a course of $1 \mathrm{~g}$. streptomycin intramuscularly daily for 5 days produced no improvement.

At this stage the diagnosis was changed to gumma of the penis and the patient was started on a course of $10 \mathrm{gr}$. potassium iodide three times a day and weekly injections of $0.3 \mathrm{~g}$. bismuth intramuscularly. The lesion responded promptly to this treatment and was completely healed in 4 weeks.

A biopsy of the lesion was performed before antisyphilitic treatment was given and the following report was received from the pathologist:

Chronic inflammatory changes compatible with a gumma.

Further investigations revealed no abnormality in the cerebrospinal fluid and radiological examination of the heart was normal. Treatment was completed by a course of penicillin therapy, 600,000 units daily for 12 days. 
Case 4, a white labourer, aged 53, presented at the Whitechapel Clinic, London Hospital, with a history of swelling of the prepuce, and the appearance of a painless penile ulcer of 4 days' duration following sexual exposure. He gave a past history of urethral discharge and a penile sore 37 years previously, which had been treated with medicine and irrigations. 31 years later (in 1949) gastroenterostomy had been performed at the London Hospital for duodenal ulceration and pyloric stenosis. In the post-operative period he had developed acute retention of urine and was found to have a urethral stricture. Serological tests for syphilis had been positive and physical examination had revealed pupillary abnormalities only. His cerebrospinal fluid had shown a normal cell count, $30 \mathrm{mg}$. protein, and a positive WR ( 1 in 20 dilution). The Lange curve was 1112211 . Treatment with bismuth injections and potassium iodide by mouth was started, but the patient had defaulted after receiving 6 injections, and was not seen again for 5 years.

Examination.-There was gross oedema of the prepuce. In the coronal sulcus there was a deep punched-out ulcer $1 \times \frac{1}{2} \times \frac{1}{2}$ in. deep, with a greenish sloughing base (Fig. 5). There was slight bilateral enlargement of the inguinal lymph nodes. The right pupil was larger than the left, and irregular in outline, and did not react to

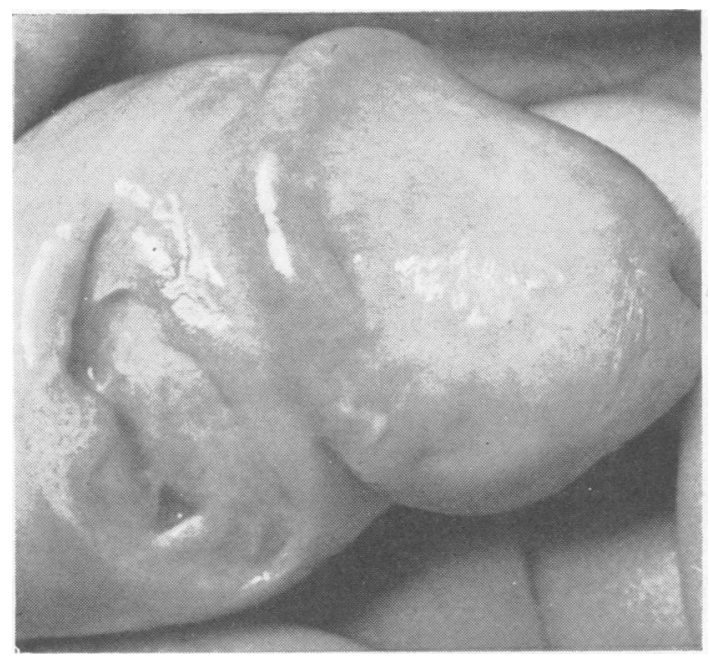

FIG. 5.-Gumma of coronal sulcus. (CASE 4)

light. The tendon reflexes were brisk and equal and the plantar reflexes both flexor. The blood pressure was $160 / 100$, but no other abnormalities, were found in the cardiovascular system.

Laboratory Investigations.-Serological tests showed a positive WR 4 units; Frei and Itô-Rienstierna intradermal tests were negative. Biopsy from the edge of the ulcer showed abundant infiltration of the floor and edge of the ulcer with polymorphonuclear leucocytes.
Treatment.-Bismuth injections and potassium iodide by mouth were given and the ulcer healed satisfactorily. The patient defaulted before penicillin therapy could be given and has not been seen since.

Case 5, a white male, aged 32, complained that 6 months before attending the Whitechapel Clinic, London Hospital, he had developed two small painless ulcers on the glans penis, which had disappeared spontaneously in 5 to 6 weeks; 2 weeks before attending the hospital the ulceration had recurred, this time in three different areas, and was associated with redness of the glans penis. These lesions were entirely painless. He had been married for 10 years and denied extra-marital exposure. There was no history of primary or secondary syphilis or of any other past illness.

Examination.-He was uncircumcised. There were several soft, raised, reddish-blue areas on the dorsum of the glans penis, and three ulcerated areas with punchedout margins and yellow sloughing bases (Fig. 6). There was no induration of the lesions and the inguinal lymph nodes were not palpable. The rest of the physical examination showed no abnormality.

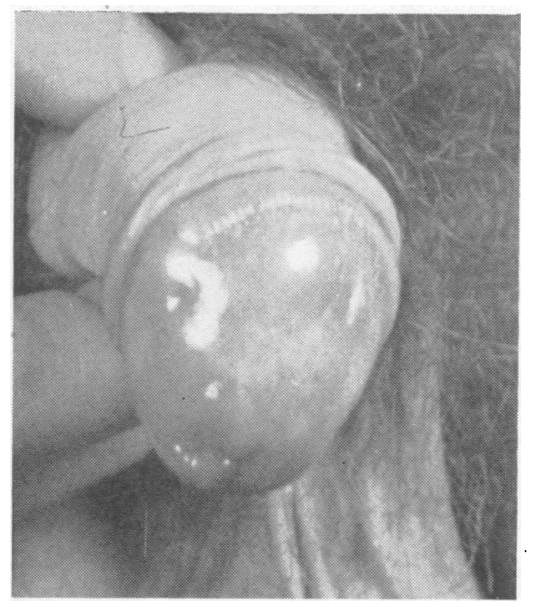

FIG. 6.-Multiple gummatous ulcers of glans penis. (CASE 5)

Laboratory Investigations.-Three dark-ground examinations of serum from the lesions were negative for $T$. pallidum. The blood WR was positive, and the PPR was positive 1 in 128; Frei and Itô-Rienstierna intradermal tests were negative. The cerebrospinal fluid was normal and chest $x$ rays and cardioscopy revealed no significant abnormality. Serological tests and physical examination performed on the patient's wife were negative.

Treatment.-He was given procaine penicillin 600,000 units intramuscularly daily for 10 days and $0.3 \mathrm{~g}$. bismuth intramuscularly for 10 weeks. The lesion responded satisfactorily to anti-syphilitic treatment but 
9 months after treatment there was still some bluish discolouration of the glans penis.

\section{Summary}

Details are given of five cases of gumma of the penis recently treated at three London teaching hospitals. Biopsy was performed on three of the lesions and the diagnosis was confirmed histologically in two cases. One patient also had a gumma of the lung.

We should like to thank Mr. Ambrose King, F.R.C.S., and Dr. C. S. Nicol for permission to record these cases.
We should also like to thank the photographic departments of St. Bartholomew's Hospital, St. Thomas's Hospital, and the London Hospital for the illustrations.

\section{REFERENCES}

Berdal, H. (1902). "Traité Pratique de la Syphilis". Maloine, Paris. Chapuis, Colé, et Duperrat (1954). Bull. Soc. franc. Derm. Syph., Fournier, A. (1906). "Traité de la Syphilis", Vol. 1, p. 113; Vol. 2, p. 209. Rueff, Paris.

Hahn, R. D. (1947). Amer. J. Syph., 31, 542.

Koyosu, Y. (1929). Lues, 4, 165.

Mariantschik, L. P. (1929). Zbl. Chir., 56, 1171

Schmidt, F. R., Jaramillo, R., and Donghi, A. (1950). Amer. J. Syph., 34, 182 .

Wise, F. (1918). J. cutan. Dis., 36, 589.

(1919). Ibid., 37, 358. 